\title{
Is catechol-o-methyltransferase gene polymorphism a risk factor in the development of premenstrual syndrome?
}

\author{
Esma Ozturk Deveci', Adnan Incebiyik', Salih Selek², Aysun Camuzcuoglu', Nese Gul Hilali ${ }^{1}$, Hakan Camuzcuoglu' \\ Mehmet Emin Erdal ${ }^{3}$, Mehmet Vural ${ }^{1}$ \\ 'Department of Gynecology and Obstetrics, Faculty of Medicine, Harran University, Sanliurfa; ${ }^{2}$ Psychiatry Department, Faculty of Medicine, Istanbul \\ Medeniyet University, Istanbul; ${ }^{3}$ Medical Faculty, Department of Medical Biology and Genetics, Mersin University, Mersin, Turkey
}

Objective: The objective of this study was to investigate whether there was a correlation between catechol-o-methyltransferase (COMT) gene polymorphism, which is believed to play a role in the etiology of psychotic disorders, and premenstrual syndrome (PMS).

Methods: Fifty-three women with regular menstrual cycles, aged between 18 and 46 years and diagnosed with PMS according to the American Congress of Obstetrics and Gynecology criteria were included in this study as the study group, and 53 healthy women having no health problems were selected as the controls. Venous blood was collected from all patients included in the study and kept at $-18^{\circ} \mathrm{C}$ prior to analysis.

Results: There was no significant difference between the groups in terms of demographic features such as age, body mass index, number of pregnancies, parity, and number of children. No statistically significant difference was observed in terms of COMT gene polymorphism ( $p=0.61)$ between women in the PMS and the control groups. However, a significant difference was found between arthralgia, which is an indicator of PMS, and low-enzyme activity COMT gene (Met/Met) polymorphism $(p=0.04)$.

Conclusion: These results suggested that there was no significant relationship between PMS and COMT gene polymorphism. Since we could not find a direct correlation between the COMT gene polymorphism and PMS, further studies including alternative neurotransmitter pathways are needed to find an effective treatment for this disease.

Keywords: Catechol-o-methyltransferase; Etiology; Neurotransmitter; Premenstrual syndrome

\section{Introduction}

Premenstrual syndrome (PMS) is defined as the psychological and physiological symptoms occurring in the luteal phase of the menstrual cycle, improving with menstruation and affecting the familial and social relationships of individuals [1,2]. Between $20 \%$ and $95 \%$ of the women in the reproductive age group are affected by these con-

Received: Feb 21, 2014 · Revised: May 20, 2014 · Accepted: May 21, 2014 Corresponding author: Adnan Incebiyik

Department of Gynecology and Obstetrics, Harran University School of Medicine, Yenisehir Campus, 63300, Sanlıurfa, Turkey

Tel:+904143183027 Fax:+904143183192 E-mail:dr.aincebiyik@gmail.com

This is an Open Access article distributed under the terms of the Creative Commons Attribution Non-Commercial License (http://creativecommons.org/licenses/by-nc/3.0/) which permits unrestricted non-commercial use, distribution, and reproduction in any medium, provided the original work is properly cited. ditions $[1,3,4]$. The etiology of PMS is not fully understood. However, it is proposed that gonadal hormones and neurotransmitters in the central nervous system play an important role in the pathophysiology of the disease, because PMS occurs during ovulatory menstrual cycles $[3,4]$.

In women who have a genetic predisposition, cyclic changes in steroid hormones are believed to play a role in the development of the affective symptoms of PMS [3]. The estrogen hormone, which is metabolized via the catechol-o-methyltransferase (COMT) pathway and the central nervous system effects of the COMT enzyme, is itself proposed to be a possible factor in mood regulation [5]. Therefore, polymorphism in the COMT enzyme, through steroid hormone metabolism, may be related to the mood symptoms of PMS.

Serotonin has been most implicated neurotransmitter in the etiolo- 
gy of PMS. Serotonin transporter-linked polymorphic region (5-HTTLPR) polymorphism was compared between patients with premenstrual dysphoric disorder whose psychological factors are predominant in the PMS spectrum and healthy control subjects, but no significant correlation was found [6]. Given the challenges in the diagnosis and treatment of PMS, it is obvious that the identification of biological markers associated with a tendency towards PMS would contribute both to the understanding of the psychobiological basis of the PMS and to the establishment of early treatment plans.

COMT is the enzyme involved in the catabolism of dopamine and the other catecholaminergic neurotransmitters in the synaptic area $[7,8]$. There are many articles showing the relationship between polymorphism occurring in the gene that codes the COMT enzyme and psychiatric disorders such as schizophrenia [7], bipolar disorder [9,10] and Parkinson's disease [11]. Although the catabolism of serotonin is not associated with COMT, polymorphism that may occur in this gene has been demonstrated to adversely affect the therapeutic success of the selective 5-HT reuptake inhibitors, which are used for the treatment of PMS [12]. Additionally, it has been shown that serotonin inhibits the COMT enzyme in vitro. For this reason, more studies are needed to understand the modulating effect of a serotonergic system on COMT and vice versa [13].

In this study, we aimed to investigate whether there was a correlation between COMT gene polymorphism, which plays a role in the etiology of many psychiatric disorders [14], and PMS, which produces symptoms such as depression and anxiety.

\section{Methods}

The present study was conducted at the Department of Gynecology and Obstetrics, Department of Psychiatry, and the Department of Molecular Biology and Genetics between January 2011 and December 2011. The design of the study accorded to the guidelines of the Declaration of Helsinki (Second revision, 2008), and was approved by the Institutional Ethics Committee. All women participating in the study were comprehensively informed prior to the procedure, and their written consent was obtained.

One hundred eighty-two women were evaluated for the study in a one-year period. Fifty-four women who had irregular menses, had a chronic disease, were receiving hormonal contraception methods, were pregnant, and/or were going to undergo gynecological surgery were excluded from the study. In addition, 22 women who were unwilling to come for the follow-up examinations during the study were not included in this study. A total of 106 women, including 53 PMS patients aged between 18 and 46 years with regular menstrual cycles (between 21 days and 35 days), and 53 healthy controls were recruited (Figure 1). The PMS diagnosis was established according to the American Congress of Obstetrics and Gynecology 2000 diagnostic criteria. In brief, PMS was diagnosed as follows: a patient was required to report at least one of the affective symptoms (depression, angry outbursts, irritability, anxiety, confusion, or social withdrawal) and to report at least one of the somatic symptoms (breast tenderness, abdominal bloating, headache, or swelling of extremities) during the five days before menses in each of the three prior menstrual cycles.

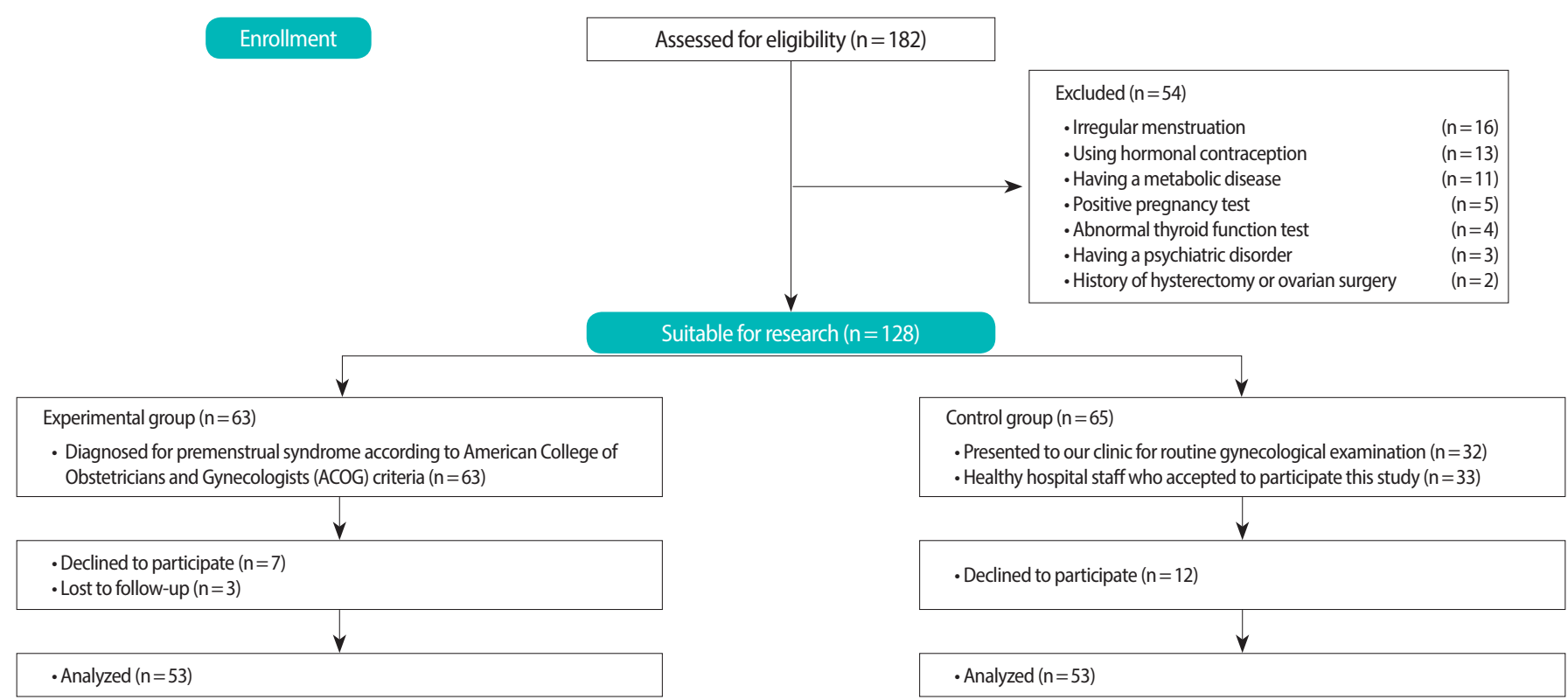

Figure 1. Flow of participants through the study. 
The symptoms had to be relieved within four days of menstruation onset without recurrence until at least the 13th cycle day [3]. The PMS diagnoses were confirmed by prospective daily symptom ratings for 2-3 menstrual cycles during the screening period [15]. The control group was selected among women in the same age group who were admitted to our clinic for routine gynecological examination and volunteered to participate in the study.

All of the women included in the study underwent general physical examinations, pelvic examinations, and smear testing at admission. Urine pregnancy tests and thyroid function tests were studied in order to rule out any symptoms that might cause complaints similar to PMS. Furthermore, the women involved in the study were reviewed by the psychiatry department in order to exclude psychiatric disorders that might be confused with PMS.

\section{Exclusion criteria}

Women suffering from chronic illnesses such as thyroid and metabolic disease, psychiatric disorders like psychosis and bipolar disorder, and irregular menstrual cycles; those who were pregnant or were suspected to be pregnant; breastfeeding women; those using hormonal contraceptives, selective serotonin reuptake inhibitors, or antidepressive drugs; and those who had undergone hysterectomies or ovarian surgery were excluded from the study.

\section{Blood collection}

All blood samples were obtained in the morning when the patients were fasting from the antecubital vein without inhibiting the venous blood flow, using plastic syringes. The total sample volume was 10 $\mathrm{mL}$. Of the samples, $5 \mathrm{~mL}$ was aliquoted for laboratory tests. The remaining $5 \mathrm{~mL}$ of blood was put into tubes containing ethylenediaminetetraacetic acid, sent immediately to the biochemical laboratory, and kept at $-18^{\circ} \mathrm{C}$ until the analysis.

\section{Molecular genetic analysis of COMT}

DNA was extracted from the blood samples collected from the women in the PMS and control groups and put into tubes containing ethylenediaminetetraacetic acid by using the salt precipitation method. Primers and TaqMan probes for COMT gene Val ${ }^{158}$ Met (c.1947 G > A, rs4680) were created from the Z26491 sequence by using the Primer Express 3.0 (Applied Biosystems) program. Genotypes of the COMT gene Val ${ }^{158}$ Met (c.1947 G > A, rs4680) polymorphism were defined through a real-time polymerase chain reaction (RT-PCR) by using a pair of 900-nmol primers (COMT-F 5'-CATCACCCAGCGGATGGT-3' and COMT-R 5'-TCAGGCATGCACACCTTGTC-3') and a pair of 200-nmol TaqMan props (COMT-PrA 5'-VIC-ATTTCGCTGGCATGAA-NFQ-MGB-3' and COMT-PrG 5'-FAM-ATTTCGCTGGCGTGAA-NFQ-MGB-3') synthesized by Applied Biosystems, Foster City, CA, USA.
Based on the previous literature, COMT genes were divided into three subgroups as high-activity homozygous (Val/Val), heterozygous (Val/Met), and low-activity homozygous (Met/Met) [11].

\section{Statistical analysis}

SPSS ver. 15.0 software for Windows (SPSS Inc., Chicago, IL, USA) was used for the statistical analysis. The data obtained from the patient and control groups were primarily determined by employing the Hardy-Weinberg principle of concordance. For the analysis of the Hardy-Weinberg equilibrium, the actual genotype frequency was compared with the Hardy-Weinberg-based expected genotype frequency. All data were represented as mean \pm standard deviation. The Kolmogorov-Smirnov test was used to check the data distribution. In comparisons between the patient and the control groups, an independent samples $t$-test was utilized. In the comparison of genotypic subgroups, a Pearson's chi-squared test was used. A genotypic comparison of sub-groups in terms of the mean symptoms in the PMS group was performed with the Kruskal-Wallis test. In the PMS group, the relationship between genotypes with binary variables was evaluated by the phi correlation coefficient. A " $p$ " value of less than 0.05 was considered statistically significant.

\section{Results}

Demographic characteristics of the study and control groups are summarized in Table 1. There was no significant difference between the groups in terms of demographic features such as age, height, weight, body mass index, number of pregnancies, and parity. The genotype frequency conformed to the Hardy-Weinberg equilibrium in both groups $\left(\chi^{2}=0.587, p=0.38\right)$.

While the number of $\mathrm{Val} /$ Met polymorphisms in the premenstrual group was higher than that in the control group, Met/Met and Val/ Val polymorphisms were higher in the control group. However, no statistically significant difference was found between the two groups in terms of high-activity homozygous (Val/Val), heterozygous (Val/ Met), and low-activity homozygous (Met/Met) COMT gene polymor-

Table 1. Demographic data for the premenstrual syndrome (PMS) group and the control group

\begin{tabular}{lccc}
\hline Characteristic & $\begin{array}{c}\text { PMS group } \\
(\text { mean } \pm \text { SD) }\end{array}$ & $\begin{array}{c}\text { Control group } \\
(\text { mean } \pm S D)\end{array}$ & $p$-value \\
\hline Age $(\mathrm{yr})$ & $30.55 \pm 5.92$ & $28.62 \pm 7.21$ & 0.136 \\
Height $(\mathrm{cm})$ & $162.24 \pm 5.17$ & $163.13 \pm 6.80$ & 0.452 \\
Weight $(\mathrm{kg})$ & $69.08 \pm 12.17$ & $67.06 \pm 11.88$ & 0.389 \\
Body mass index $\left(\mathrm{kg} / \mathrm{m}^{2}\right)$ & $26.13 \pm 3.83$ & $25.27 \pm 4.54$ & 0.294 \\
Gravida & $1.62 \pm 1.95$ & $1.13 \pm 1.68$ & 0.168 \\
Parity & $1.43 \pm 1.67$ & $1.13 \pm 1.68$ & 0.355 \\
\hline
\end{tabular}




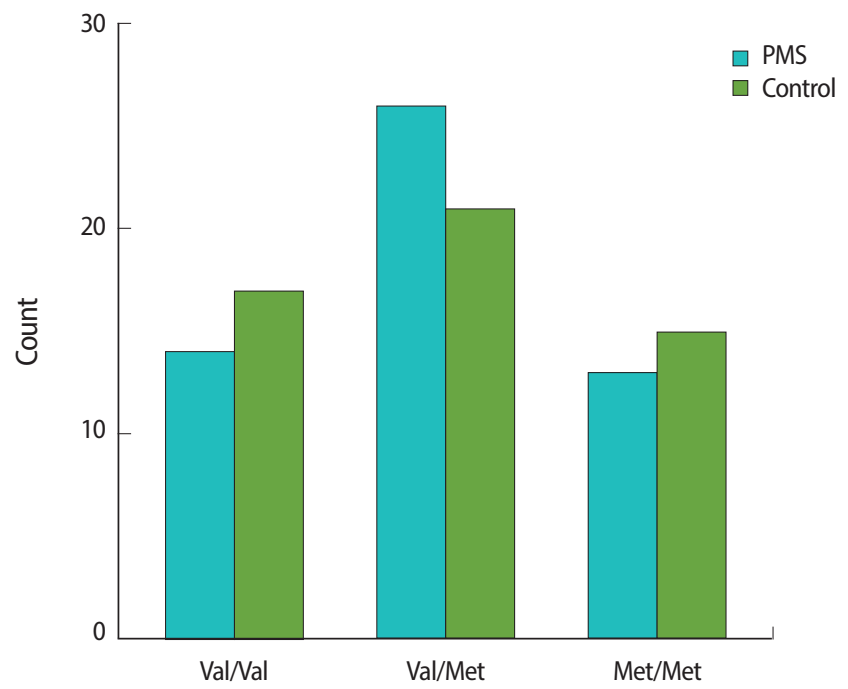

Figure 2. Prevalence of catechol-o-methyltransferase gene polymorphism among the premenstrual syndrome group and the control group. PMS, premenstrual syndrome; Val/Val, valine/valine; Val/Met, valine/methionine; Met/Met, methionine/methionine.

phisms ( $p=0.61$ ) (Figure 2).

No significant difference was observed between the groups in terms of the responses given to questions about fatigue, insomnia, abdominal pain and bloating, nausea, headache, pelvic pain, tension, loneliness, anger, depression, and COMT gene polymorphism ( $p>0.05)$; however, a significant difference between arthralgia and low activity of the COMT gene (11 of 13 patients, $84.6 \%, p=0.04$ ) was observed.

\section{Discussion}

To the best of our knowledge, although 5-HTTLPR and estrogen receptor-alpha intron 4 polymorphism (ESR1) genes were previously studied in patients with premenstrual dysphoric disorder [5,6], this study is the first to investigate the relationship between PMS and the COMT enzyme polymorphism, which is involved in the catabolism of the neurotransmitters. In this study, in which we investigated whether there was a correlation between COMT gene polymorphism-which has been believed to play a role in the development of many psychiatric disorders - and PMS, we found that a significant relationship existed only between arthralgia and low activity of the COMT gene.

PMS, which is the most commonly observed clinical complaint in women in the reproductive age group [15], is a major health problem that decreases health-related quality of life, reduces business productivity, and increases health care costs $[16,17]$. Furthermore, premenstrual periods in which psychotic episodes, physical complaints, and even suicide attempts are more frequent represent higher rates of hospitalization and increased need for emergency treatment [4].
Although this disease, which results from complaints relating to menstruation, has long been known, its pathophysiology is not fully understood. Contradictory results were obtained in studies conducted to consider whether vitamin deficiencies involved in the metabolism of neurotransmitters were related to development of the disease [18-21]. Studies conducted to verify whether minerals such as iron, potassium, zinc, and magnesium play a role in moderating the development of PMS suggest that the intake of these minerals might be beneficial in prevention of the disease [22]. The most widely accepted current theory holds that gonadal steroid hormones and cyclic changes in the level of central neurotransmitters affect mood and behavior during the luteal phase and trigger the disease in women who are predisposed to PMS [3]. Despite the evidence demonstrating the role of $\beta$-endorphin and gamma-aminobutyric acid in the etiology of PMS, serotonin is the most accused neurotransmitter $[23,24]$. However, a clear relationship between serotonin and PMS has not yet been proven [6].

A clinical condition that is a more severe form of PMS with prominent psychological symptoms is defined as "premenstrual dysphoric disorder" [25]. Numerous studies have demonstrated the relationship between premenstrual dysphoric disorder and psychiatric disorders such as major depression [26], mood disorders [27], and postpartum depression [28]. We speculated that a disorder related to dopamine function might contribute to the development of PMS since depression is a disorder related to dopaminergic function and is one of the affective signs of PMS.

COMT is one of the most important enzymes involved in dopamine catabolism in the prefrontal cortical region. The enzyme is coded by the COMT gene located in the 22nd chromosome. This gene presents a genetic polymorphism (Val ${ }^{158}$ Met, G1221A) with two common allelic variants (Val ${ }^{158}$ Met polymorphism; (rs4680) in which a single G/A base-pair substitution leads to a valine-to-methionine substitution at codon 158) that influence the efficiency with which dopamine is broken down in the prefrontal cortex $[7,29]$. Val allele is associated with higher enzyme activity than Met allele, and results in a lower level of dopamine in the prefrontal cortex [9]. There are several studies in the literature that show that a low level of dopamine is associated with diseases such as schizophrenia [7], bipolar disorder [9], Parkinson's disease [11], depression [30], and psychotic disease [10]. In contrast, there are also studies in the literature demonstrating that there is no relationship between COMT gene polymorphism and psychiatric disorders such as Parkinson's disease [31] and schizophrenia $[32,33]$. In the present study, we investigated whether PMS, which causes psychological symptoms such as depression, anxiety, angry outbursts, and confusion, was correlated with COMT gene polymorphism; we could not find a statistically significant difference between the healthy controls and the PMS patients $(p=0.61)$ (Figure 2$)$. There 
is no other study in the literature demonstrating a relationship between PMS and COMT gene polymorphism. Therefore, further studies are needed to compare our results.

PMS is a clinical condition with affective and somatic symptoms. The most common somatic symptoms include abdominal bloating and fatigue [34], along with arthralgia [35]. According to the correlation coefficient test that we conducted on COMT gene polymorphism and PMS, a significant correlation was only found to exist between arthralgia and the low-activity of the COMT gene polymorphism $(p=0.04)$.

This study has several limitations. First, there are difficulties in the establishment of a PMS diagnosis due to the subjective interpretation of the symptoms. However, the use of the American Congress of Obstetrics and Gynecology criteria that are commonly used to establish the diagnosis of PMS is one of the strengths of our study. A second limitation was that gene polymorphism was studied only on the community living in our region, because the study was locally conducted. Different results would be expected if the study were conducted with populations of different ethnic origins. Another limitation is the low total number of cases in the study group.

In conclusion, our findings from this study demonstrated that there is no correlation between COMT gene polymorphism and PMS. On the other hand, new study designs that will help us understand the etiology and pathophysiology of the syndrome and help to develop or identify effective treatment methods to solve the problem in the future are suggested.

\section{Conflict of interest}

No potential conflict of interest relevant to this article was reported.

\section{References}

1. O'Brien PM, Backstrom T, Brown C, Dennerstein L, Endicott J, Epperson $\mathrm{CN}$, et al. Towards a consensus on diagnostic criteria, measurement and trial design of the premenstrual disorders: the ISPMD Montreal consensus. Arch Womens Ment Health 2011;14:13-21.

2. Zarei S, Mosalanejad L, Ghobadifar MA. Blood glucose levels, insulin concentrations, and insulin resistance in healthy women and women with premenstrual syndrome: a comparative study. Clin Exp Reprod Med 2013;40:76-82.

3. Wichianpitaya J, Taneepanichskul S. A comparative efficacy of low-dose combined oral contraceptives containing desogestrel and drospirenone in premenstrual symptoms. Obstet Gynecol Int 2013;2013:487143.

4. Cirillo PC, Passos RB, Bevilaqua MC, Lopez JR, Nardi AE. Bipolar disorder and Premenstrual Syndrome or Premenstrual Dysphoric Disorder comorbidity: a systematic review. Rev Bras Psiquiatr 2012;34:467-79.

5. Huo L, Straub RE, Roca C, Schmidt PJ, Shi K, Vakkalanka R, et al. Risk for premenstrual dysphoric disorder is associated with genetic variation in ESR1, the estrogen receptor alpha gene. Biol Psychiatry 2007;62:925-33.

6. Magnay JL, El-Shourbagy M, Fryer AA, O'Brien S, Ismail KM. Analysis of the serotonin transporter promoter rs25531 polymorphism in premenstrual dysphoric disorder. Am J Obstet Gynecol 2010;203:181 e1-5.

7. Basterra V, Sanchez-Torres AM, Rosa A, Fananas L, Cuesta MJ, Peralta V. Influence of genetic variability at the COMT gene on TMT-B performance in psychotic patients and their healthy siblings. Psychiatr Genet 2012;22:92-5.

8. Arts B, Simons CJ, Drukker M, van Os J. Antipsychotic medications and cognitive functioning in bipolar disorder: moderating effects of COMT Val108/158 Met genotype. BMC Psychiatry 2013; 13:63.

9. Benedetti F, Dallaspezia S, Locatelli C, Radaelli D, Poletti S, Lorenzi C, et al. Recurrence of bipolar mania is associated with catechol-O-methyltransferase Val(108/158)Met polymorphism. J Affect Disord 2011;132:293-6.

10. Benedetti F, Dallaspezia S, Colombo C, Lorenzi C, Pirovano A, Smeraldi E. Association between catechol-0-methyltransferase Val(108/158)Met polymorphism and psychotic features of bipolar disorder. J Affect Disord 2010;125:341-4.

11. Wu K, O'Keeffe D, Politis M, O'Keeffe GC, Robbins TW, Bose SK, et al. The catechol-O-methyltransferase Val(158)Met polymorphism modulates fronto-cortical dopamine turnover in early Parkinson's disease: a PET study. Brain 2012;135:2449-57.

12. Benedetti F, Dallaspezia S, Colombo C, Lorenzi C, Pirovano A, Smeraldi E. Effect of catechol-O-methyltransferase Val(108/158)Met polymorphism on antidepressant efficacy of fluvoxamine. Eur Psychiatry 2010;25:476-8.

13. Baldinger $P$, Hahn A, Mitterhauser $M$, Kranz GS, Friedl M, Wadsak $W$, et al. Impact of COMT genotype on serotonin-1A receptor binding investigated with PET. Brain Struct Funct 2013 Aug 9 [Epub]. http://doi.dx.org/10.1007/s00429-013-0621-8.

14. Kurnianingsih YA, Kuswanto CN, McIntyre RS, Qiu A, Ho BC, Sim K. Neurocognitive-genetic and neuroimaging-genetic research paradigms in schizophrenia and bipolar disorder. J Neural Transm 2011;118:1621-39.

15. Freeman EW, Sammel MD, Lin H, Rickels K, Sondheimer SJ. Clinical subtypes of premenstrual syndrome and responses to sertraline treatment. Obstet Gynecol 2011;118:1293-300.

16. Borenstein JE, Dean BB, Leifke E, Korner P, Yonkers KA. Differenc- 
es in symptom scores and health outcomes in premenstrual syndrome. JWomens Health (Larchmt) 2007;16:1139-44.

17. Heinemann LA, Minh TD, Filonenko A, Uhl-Hochgraber K. Explorative evaluation of the impact of severe premenstrual disorders on work absenteeism and productivity. Womens Health Issues 2010;20:58-65.

18. Chocano-Bedoya PO, Manson JE, Hankinson SE, Willett WC, Johnson SR, Chasan-Taber L, et al. Dietary B vitamin intake and incident premenstrual syndrome. Am J Clin Nutr 2011;93:1080-6.

19. Chuong CJ, Dawson EB, Smith ER. Vitamin A levels in premenstrual syndrome. Fertil Steril 1990;54:643-7.

20. Bertone-Johnson ER, Chocano-Bedoya PO, Zagarins SE, Micka $A E$, Ronnenberg AG. Dietary vitamin D intake, 25-hydroxyvitamin D3 levels and premenstrual syndrome in a college-aged population. J Steroid Biochem Mol Biol 2010;121:434-7.

21. Chuong CJ, Dawson EB, Smith ER. Vitamin E levels in premenstrual syndrome. Am J Obstet Gynecol 1990;163:1591-5.

22. Chocano-Bedoya PO, Manson JE, Hankinson SE, Johnson SR, Chasan-Taber L, Ronnenberg AG, et al. Intake of selected minerals and risk of premenstrual syndrome. Am J Epidemiol 2013;177: 1118-27.

23. Rapkin AJ, Akopians AL. Pathophysiology of premenstrual syndrome and premenstrual dysphoric disorder. Menopause Int 2012;18:52-9.

24. Marjoribanks J, Brown J, O'Brien PM, Wyatt K. Selective serotonin reuptake inhibitors for premenstrual syndrome. Cochrane Database Syst Rev 2013;6:CD001396.

25. Gupta R, Lahan V, Bansal S. Subjective sleep problems in young women suffering from premenstrual dysphoric disorder. $\mathrm{N}$ Am J Med Sci 2012;4:593-5.

26. Klatzkin RR, Lindgren ME, Forneris CA, Girdler SS. Histories of major depression and premenstrual dysphoric disorder: Evidence for phenotypic differences. Biol Psychol 2010;84:235-47.
27. Magnay JL, Ismail KM, Chapman G, Cioni L, Jones PW, O'Brien S. Serotonin transporter, tryptophan hydroxylase, and monoamine oxidase A gene polymorphisms in premenstrual dysphoric disorder. Am J Obstet Gynecol 2006;195:1254-9.

28. Sylven SM, Ekselius L, Sundstrom-Poromaa I, Skalkidou A. Premenstrual syndrome and dysphoric disorder as risk factors for postpartum depression. Acta Obstet Gynecol Scand 2013;92: 178-84.

29. He Q, Xue G, Chen C, Lu ZL, Chen C, Lei X, et al. COMT Val158Met polymorphism interacts with stressful life events and parental warmth to influence decision making. Sci Rep 2012;2:677.

30. Antypa N, Drago A, Serretti A. The role of COMT gene variants in depression: Bridging neuropsychological, behavioral and clinical phenotypes. Neurosci Biobehav Rev 2013;37:1597-610.

31. Wang Y, Yang X. Association of catechol-o-methyltransferase polymorphism (Val108/158Met) with Parkinson's disease: a meta-analysis. J Mot Behav 2012;44:365-72.

32. Cordeiro Q, Silva RT, Vallada H. Association study between the rs165599 catechol-O-methyltransferase genetic polymorphism and schizophrenia in a Brazilian sample. Arq Neuropsiquiatr 2012; 70:913-6.

33. Okochi T, Ikeda M, Kishi T, Kawashima K, Kinoshita Y, Kitajima T, et al. Meta-analysis of association between genetic variants in COMT and schizophrenia: an update. Schizophr Res 2009;110: 140-8.

34. Hartlage SA, Freels S, Gotman N, Yonkers K. Criteria for premenstrual dysphoric disorder: secondary analyses of relevant data sets. Arch Gen Psychiatry 2012;69:300-5.

35. Tjandrawinata RR, Nofiarny D, Susanto LW, Hendri P, Clarissa A. Symptomatic treatment of premenstrual syndrome and/or primary dysmenorrhea with DLBS1442, a bioactive extract of Phaleria macrocarpa. Int J Gen Med 2011;4:465-76. 